\title{
PARAMETRICAL ANALYSIS OF VACUUM CONTACT DEVICES FOR WALL CLIMBING ROBOTS
}

\author{
V. G. GRADETSKY, M. M. KNYAZKOV, E. A. SEMENOV and A. N. SUKHANOV \\ Institute for Problems in Mechanics of the Russian Academy \\ of Sciences101-1, Prospect Vernadskogo, 119526 Moscow, \\ Russiagradet@ipmnet.ru,
}

\begin{abstract}
Linearized model of vacuum contact device is presented for study of wall climbing underwater robot parameters. Features of such device design are discussed. Device includes pneumatic chamber, drive, source of vacuum and sealing.

Pneumatic chamber of device model is depicted as a changed volume with variable and constant pneumatic restrictions - throttles included on input and output of chamber. Pressure pump or ejector is used as source of the vacuum.

The results of simulation and modeling permit to find relationships between such parameters as pressure, flow rate, pressing force.

Motion-path cyclograms and pressure changing characteristics illustrate dependence between working parameters.

The obtained results of model study are used to develop calculation method for design prospective prototypes of vacuum contact devices.

Key words: wall climbing robot, vacuum contact device, parametrical analysis, simulation, modeling, calculation, design, cyclogram.
\end{abstract}

\section{Introduction}

Underwater wall climbing robots (UWCR) are intended for motion along vertical and slope surfaces in extreme underwater conditions and their supply special vacuum contact devices (VCD) for satisfy reliable contact between robot corp and surfaces. VCD includes generator of vacuum, pressure pump or ejector, corp with flexible walls, contacting with surfaces seal ring and pneumatic pressing drive for lift and lowering.

Wall climbing robots are used for technological operation producing in complex conditions and fields. There are good known examples of wall climbing robots (WCR) application for laser and mechanical cutting on nuclear power stations $[1,10,11]$, as so as for nondestructive testing [2], inspection of mechanisms in conditions of high radiation and decontamination [8], inspection of underwater construction quality [4].

Ejectors $[5,6]$ and pressure vacuum pumps of various types $[7,8]$ are applied for generation of vacuum to produce WCR and UWCR motion over ferromagnetic and nonferromagnetic surfaces. Selection of vacuum source depends on condition of application. However changing of forces as a result of variable pressure and parametrical analysis of VCD have not been developed yet in early known publications [9-14].

Parametrical analysis permits to develop more precise and reliable VCD in compare with existing up to day.

Besides working cyclograms of VCD functioning are not created.

Taking into consideration previous expertise, it was necessary to describe in this paper the following problems:

- to calculate such working parameters of VCD as pressure, flow, force; 
- to produce parametrical analysis and to design motion-path and pressure changing cyclograms.

\section{Methods and experiments}

It is possible to use several VCD on every leg of WCR, for example three (Fig. 1, a, b) to satisfy it reliable motion over surfaces. Under consideration prototype of UWCR is intended for inspection underwater vertical surface.

Design diagram of one VCD (Fig. 2) includes following components - elastic seal 1, step bearing 2, chamber 3, vacuum generator 4, pressing drive 5, position sensor 6 , plunger 7 . Distance between VCD plane and surface is denote like gap h, displacement of the plunger is denote like $y$. Pressures $\mathrm{P}_{\mathrm{s}}$ and $\mathrm{P}_{\mathrm{a}}$ are forming by control system and intended for plunger motion up and down. Vacuum generation 4 is intended for creation absolute pressure $\mathrm{P}_{2}$.

Environment pressure PB depends on UWCR depth in water. In the air area $\mathrm{P}_{\mathrm{B}}=\mathrm{P}_{\mathrm{a}}$, since it is atmospheric pressure. Output chanel of vacuum generator is removed from water and is connected with environment.

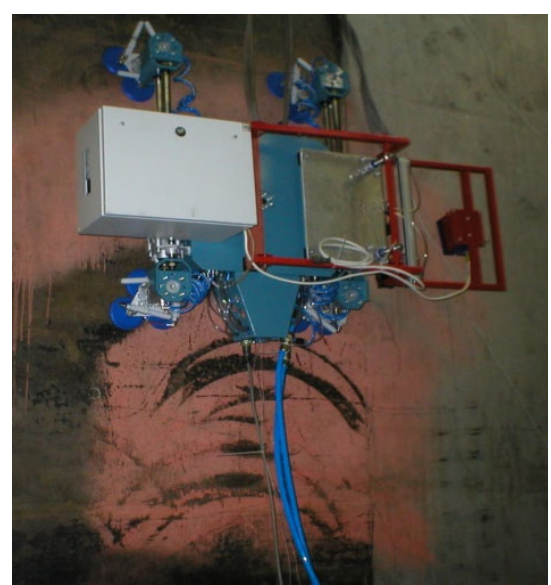

a) the appearance of the robot;

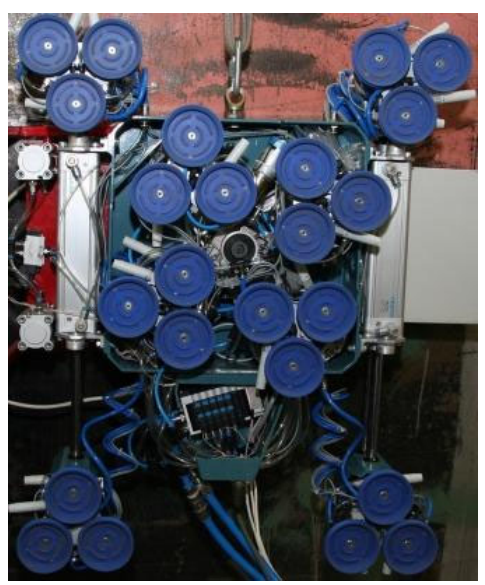

b) a system of vacuum contact devices.

Figure 1 Vertical movement robot for carrying out the technological operation "surface inspection".

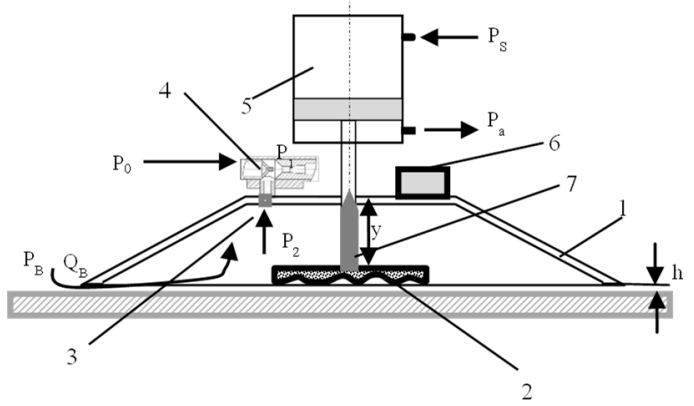

Figure 2 Constructive scheme of a vacuum contact device with a drive to send to the displacement surface.

There are different mood of VCD operations what is determined by initial gap $\mathrm{h}$ and quality of surface. When $\mathrm{h}=0$ vacuum generator pump out the mixture of water and air from hermetic chamber 3 , the load is minimal. If initial gap $h \neq 0$, the chamber 3 is not hermetic and evacuation will be with additional mixture. In this case the load is increasing in accordance with nonlinear characteristic of "nozzle-flap" throttle where nozzle is orifice of VCD and flap is distance between plane of VCD and surface over which robot is moved. 


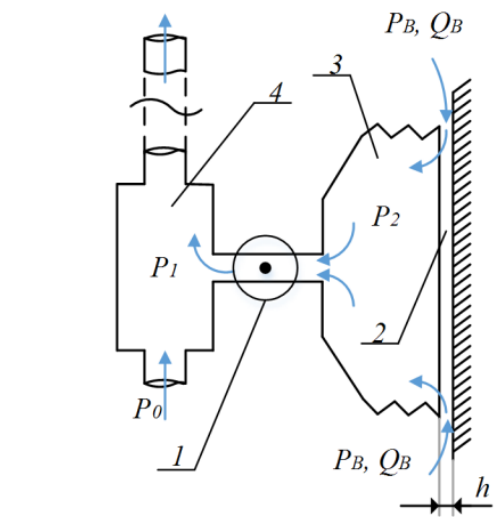

Figure 3 Design flow pattern in a vacuum contact device of a wall climbing robot.

The diagram of calculation model (Fig. 3) includes chamber with two pneumatic restrictions one of it has constant cross section and connects chamber with vacuum generator and other of it has variable cross section that is "nozzle flap" throttle.

Suggested VCD calculation model includes nonlinear characteristic of "nozzle-flap" throttle. The following admissions are taking in consideration:

$$
\begin{array}{ll}
\text { - } & \text { flow is indissolubly; } \\
\text { - } & \text { density is neutralized; } \\
\text { - } & \text { friction force is unidimensional; } \\
& \text { load is nonlinear of "nozzle-flap" throttle. }
\end{array}
$$

It is demanded to determine such VCD working parameters as pressure, flow, force.

To solve the problems it is possible to use and analyze the diagram of calculation model that presented at Fig. 3. The nonlinear load of "nozzle-flap' throttle depends on flap size h.

By means following designations: $\mathrm{d}_{1}$ and $\mathrm{d}_{2}$ - diameters of pneumatic restrictions 1 and 2 recordingly, $\mathrm{P}_{1}, \mathrm{P}_{2}, \mathrm{P}_{3}$ - absolute pressures respectively on output of chamber, inside of it and on external environment, $\mathrm{P}$ - supply pressure of vacuum generator.

Mass flow transfer across throttles 1 and 2 are equal according to

$$
\begin{aligned}
& Q_{1}=f_{1}\left[\frac{2}{R T} P_{1}\left(P_{2}-P_{1}\right)\right]^{1 / 2} \\
& Q_{2}=f_{2}\left[\frac{2}{R T} P_{2}\left(P_{\mathrm{B}}-P_{2}\right)\right]^{1 / 2}
\end{aligned}
$$

To use formula of mass flow equality [9] through throttles 1 and 2 and indissolubly equation, it is possible to receive that

$$
f_{1}\left[\frac{2}{R T} P_{1}\left(P_{2}-P_{1}\right)\right]^{1 / 2}=f_{2}\left[\frac{2}{R T} P_{2}\left(P_{B}-P_{2}\right)\right]^{1 / 2}
$$

Taking into consideration that here $\mathrm{f}_{1}$ and $\mathrm{f}_{2}$ are effective areas of pneumatic restrictions 1 and $2, \mu_{1}$ and $\mu_{2}$ - are flow coefficients over restrictions, $\mathrm{R}-$ is gas constant, we receive that

$\mu_{1} \frac{\pi d_{1}^{2}}{4}\left[\frac{2}{R T} P_{1}\left(P_{2}-P_{1}\right)\right]^{1 / 2}=\mu_{2} \pi d_{2} h\left[\frac{2}{R T} P_{2}\left(P_{B}-P_{2}\right)\right]^{1 / 2}$

To find value of flap $\mathrm{h}$ as a function of pressures, it possible to write: 
$h=\frac{\mu_{1} d_{1}^{2}}{4 \mu_{2} d_{2}}\left[\frac{P_{1}\left(P_{2}-P_{1}\right)}{P_{2}\left(P_{B}-P_{2}\right)}\right]^{1 / 2}$

where $h_{0}$ is initial gap between end of VCD and surface, and $h_{0} \geq h>0$.

To determine a pressure inside of chamber let us to take the square of the value of $h$, after what it is needed to solve square equation relative to pressure $\mathrm{P}_{2}$

$$
P_{2}^{2}-P_{2}\left(P_{B}-P_{1} \frac{a^{2}}{h^{2}}\right)-\frac{a^{2}}{h^{2}} P_{1}^{2}=0, \text { where } a=\frac{\mu_{1} d_{1}^{2}}{4 \mu_{2} d_{2}^{2}}
$$

After corresponding transformation we receive value of $\mathrm{P} 2$ pressure depending of $\mathrm{d}_{1}, \mathrm{~d}_{2}, \mathrm{~h}$

$$
P_{2}=\frac{P_{B}}{2}-\frac{1}{2} \cdot \frac{a^{2}}{h^{2}} P_{1}+\left[\frac{P_{B}^{2}}{4}-\frac{1}{2} \cdot \frac{a^{2}}{h^{2}} \cdot P_{B} \cdot P_{1}+\frac{a^{2}}{h^{2}}\left(\frac{1}{4} \cdot \frac{a^{2}}{h^{2}}+1\right) P_{1}^{2}\right]^{1 / 2}
$$

This equation is nonlinear and links between VCD parameters are found by means parametrical analysis.

\section{Parametrical analysis and for cyclograms design pressure changing and motion-path}

The goal of parametrical analysis is elucidation of mechanism of parameters interactions. Designations of parameters are shown in Fig. 3.

The links between parameters are delivered at the diagrams Fig. 4-7 on relative coordinates.

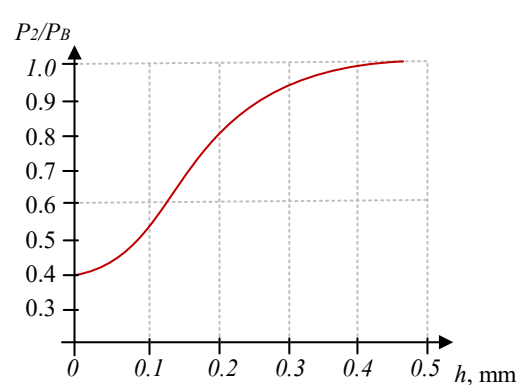

Figure 4 Dependence between dimensionless quantity of pressure $\mathrm{P}_{2} / \mathrm{P}_{\mathrm{B}}$ gap h.

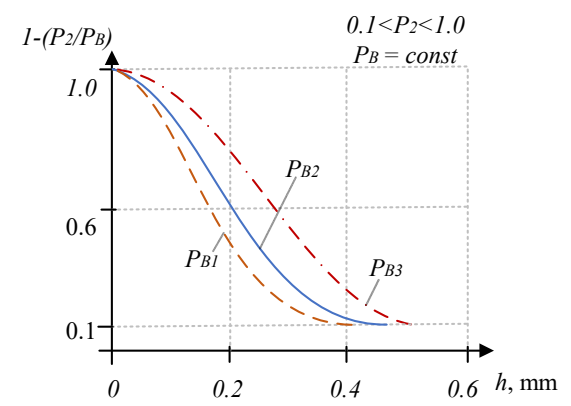

Figure 6 Pressure difference across the gap when $0<\mathrm{P}_{2}<1,0$ and $\mathrm{P}_{\mathrm{B}}=$ const

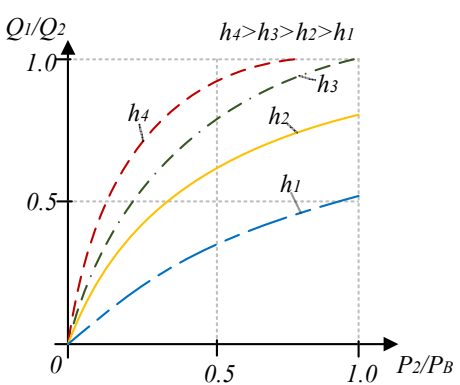

Figure 5 Dependence between dimensionless quantity of mass flow $\mathrm{Q}_{1} / \mathrm{Q}_{2}$ and pressure $\mathrm{P}_{2} / \mathrm{P}_{\mathrm{B}}$ under various $\mathrm{h}$.

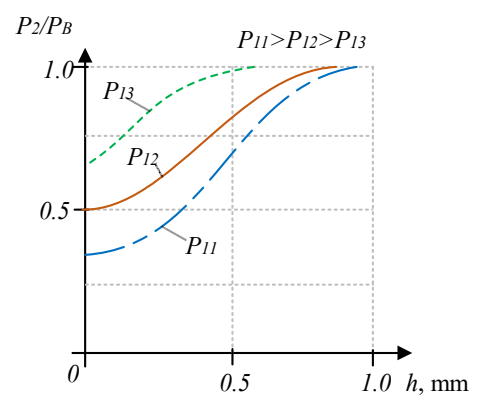

Figure 7 Pressure difference $\mathrm{P}_{2} / \mathrm{P}_{\mathrm{B}}$ across the gap $h$ under various pressure $P_{1}$

Pressure relationship $\mathrm{P}_{2} / \mathrm{P}_{\mathrm{B}}$ inside of chamber and in environment to the gap h (Fig. 4) is like exponent ratio, and $\mathrm{P}_{2}=\mathrm{P}_{\mathrm{B}}$ under $\mathrm{h}$ value is more than $0,5 \mathrm{~mm}$.

It is important to know how mass flow depends on pressure for different gaps when VCD is under action. The dependence of relative mass flow $\mathrm{Q}_{1} / \mathrm{Q}_{2}$ on pressure relationship $\mathrm{P}_{2} / \mathrm{P}_{\mathrm{B}}$ is 
presented in Fig. 5 where gap values are $\mathrm{h}_{4}>\mathrm{h}_{3}>\mathrm{h}_{2}>\mathrm{h}_{1}$ and $\mathrm{Q}_{1}$ is the mass flow in output of chamber. It is clear that $\mathrm{Q}_{1}=\mathrm{Q}_{2}$ in the case if $\mathrm{P}_{2}=\mathrm{P}_{\mathrm{B}}$.

The characteristics of pressures in relative coordinates as functions on gapes are delivered in Fig. 6 and Fig. 7, during which pressure $P_{2}$ is typically lies in the range between 0,1 and 1,0 for the cases when $P_{B}=$ const (Fig. 6), and pressure $P_{1}$ may be changed like $P_{11}>P_{12}>P_{13}$ (Fig. 7).

Nomogram (Fig. 8) presents generalized relationships between pressure parameters $\mathrm{P}_{1}, \mathrm{P}_{2}$ and gap $\mathrm{h}$. The nomogram permits to find pressure values across the gap $\mathrm{h}$ for rational value of flow.

Contact and friction forces are arised when VCD is connected with surfaces. The following equation determines force interaction in VCD (Fig. 2):

$(P s-P B) \cdot f=c y l+c y \pm N M+N m p \cdot S i g n \dot{y} \pm N$

Here $P_{s}$ - pressure in working chamber, $P_{B}$ - pressure in environment, $f-$ area of piston, $\mathrm{y}_{1}$ - initial compression of spring, cy - force of spring, $\mathrm{N}_{\mathrm{fr}}-$ friction force, $\mathrm{y}$ - displacement of piston, $\mathrm{N}$ - gravity force.

It should be pointed out that displacement of plunger may be determined as equation (8).

$y=\frac{f}{c}\left(P_{S}-P_{B}\right)-\frac{c y_{1} \pm N_{\mathrm{H}}+N_{f r} \cdot \operatorname{Sign} \dot{y} \pm N_{B}}{c}$

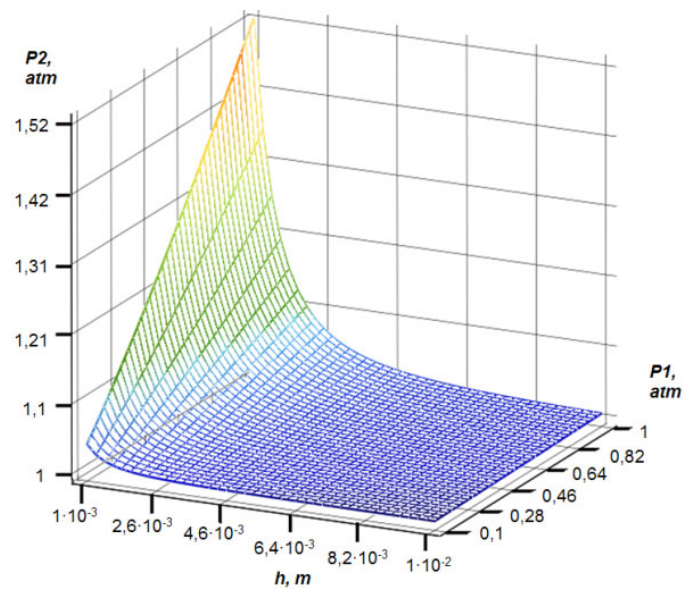

Figure 8 Generalized characteristics of pressures $P_{1}, P_{2}$ and gap $h$.

After introduction following designations (9)

$N=c y_{1} \pm N_{\mathrm{H}}+N_{f r} \cdot \operatorname{Sign\dot {y}} \pm N_{B}$

it is possible to obtain that plunger displacement $\mathrm{y}$ of $\mathrm{VCD}$ is equal as

$y=\frac{f}{c}\left(P_{s}-P_{a}\right)-\frac{N}{c}$

Function Signy் is introduced for take into consideration that friction force changes direction depends of motion direction of plunger. Sign plus corresponds to action of the spring, sign minus corresponds to vertical motion direction of plunger and piston (Fig. 2). 


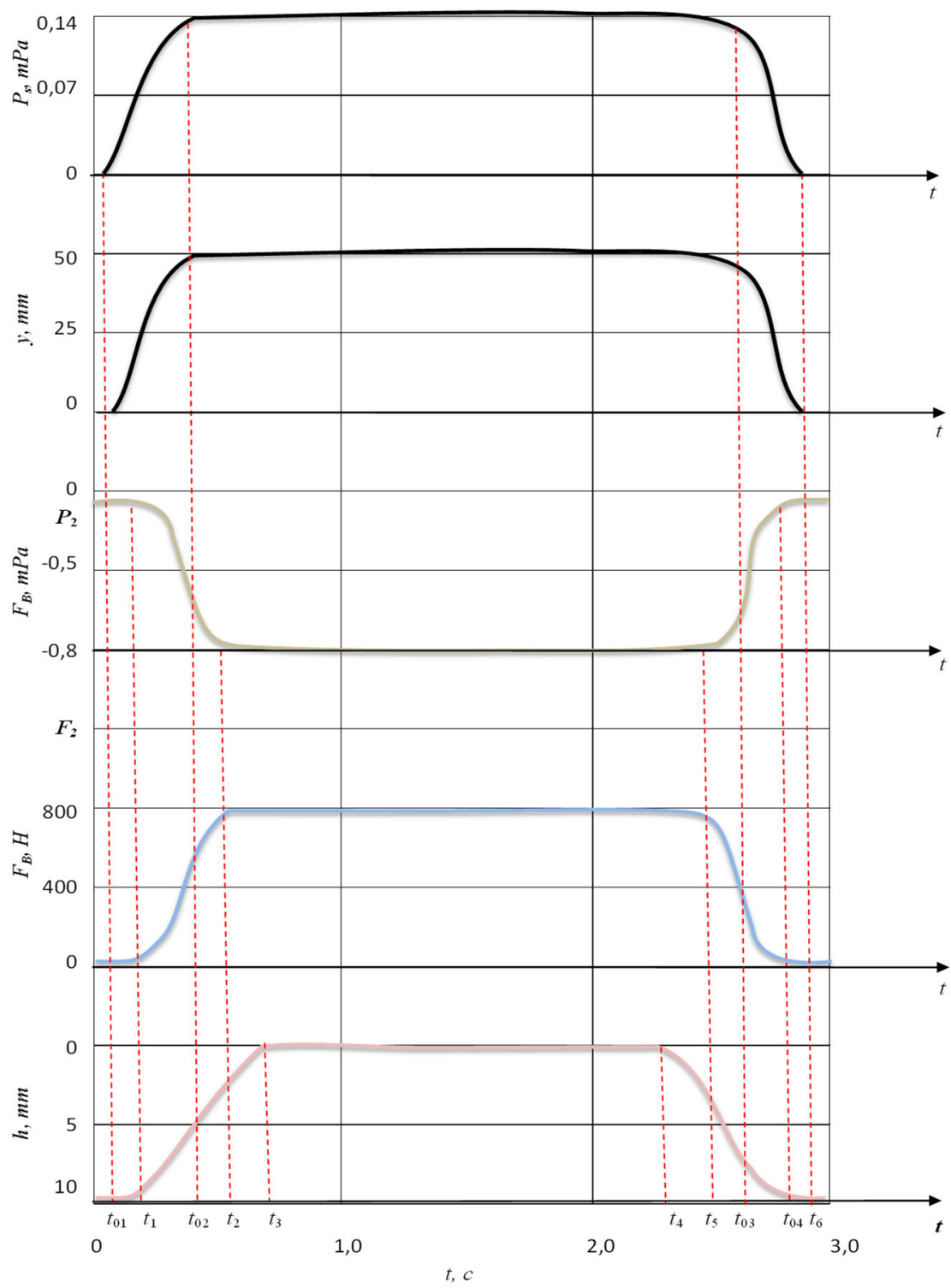

Figure 9 Transient processes inside suction chamber of vacuum contact device while operating in water environment.

The motion-path cyclogram (Fig. 9) shows the motion phases and parameter changes of VCD functioning with drive sending on contact surface. 


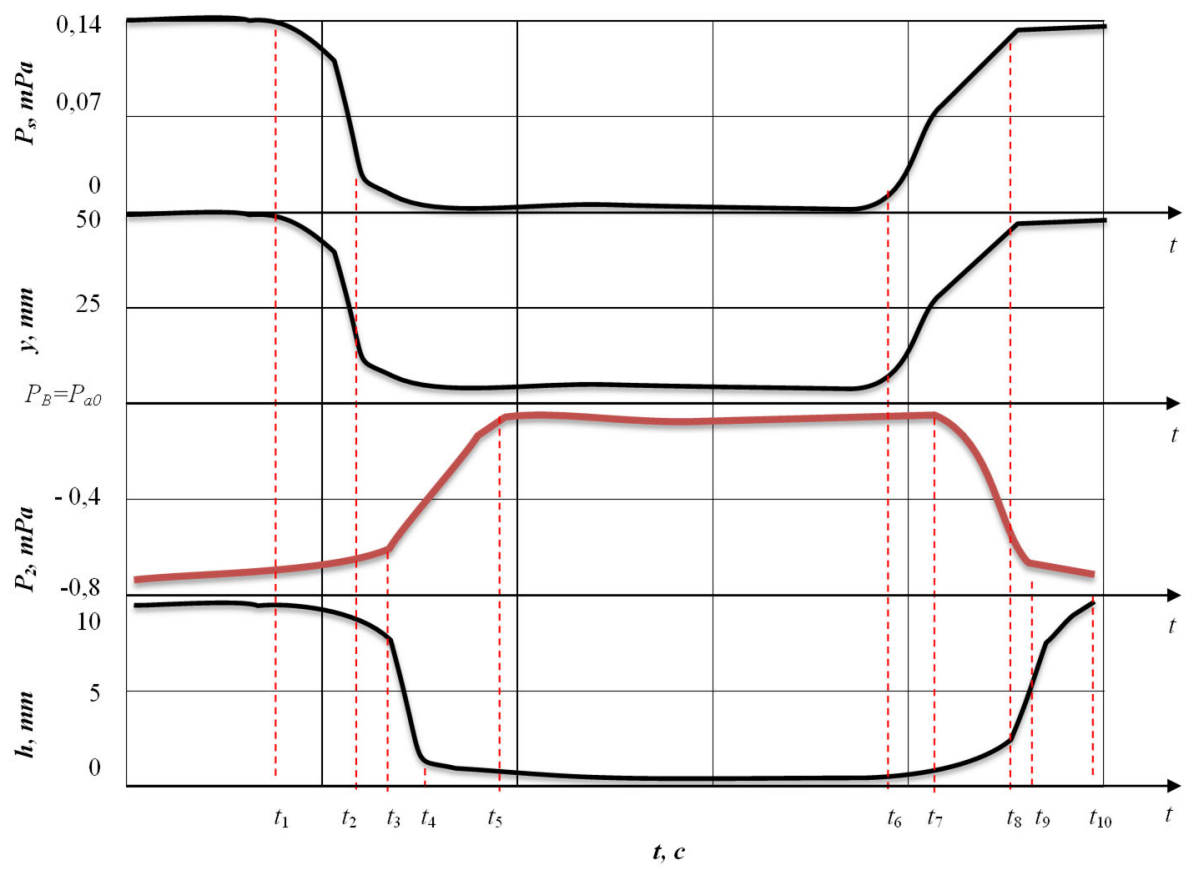

Figure $10 \mathrm{~A}$ sequence diagram of transients occurring in a VCD during operation in an aqueous medium with a reverse stroke of the finishing drive piston.

The cuclograme of VCD functioning with reverse motion of the pressing drive is presented at Fig. 10.

\section{Conclusion}

Linearized VCD model was designed for wall climbing robot application that can work on atmosphere and underwater environments. Pneumatic chamber of VCD is depicted as a changed volume with variable and constant pneumatic restrictions that were included on input and output of chamber. Parametrical analysis of VCD was delivered to calculate links between pressures, flow rates volumes, forces and to study necessary mood of operations. The results of R\&D permit to find relationships between working parameters. The motion-path cyclograms and pressure changing characteristics illustrate dependence of pressure and flow on geometrical sized of critical gap between end of VCD and surfaces along which wall climbing robots move.

The presented results of parametrical analysis study can be used to calculate mood of operations prospective prototypes of VCD for equip wall climbing robots intended to move over vertical, slope and ceiling surfaces under complex environments.

\section{Acknowledgements}

The research is supported by Russian Foundation for Basic Researches, Grant №18-08-0357

\section{References}

1. Tariq P. Sattar, Paul Hilton, MIDDMAR Faruq Howlader. Deployment of Laser Cutting Head with Wall Climbing Robot for Nuclear Decomissioning. Proceed. Of CLAWAR 2016 Inter. Conference. Advance in Cooperative Robotics, London, UK. Sept. 2016, pp. 725-732. 
2. Z. Zhao, G. Shirkoohi. Climbing Robot Design for NDT Inspection. Proceed of CLAWAR 2017 Inter Conference. Human-Centric Robotics, Porto, Portugal, Sept. 2017, 259-266.

3. Robotics in Nuclear Facilities, 1991, Special issue for Exhibition of the 11th International Conference on Structural Mechanics in Reactor Technology (SmiRT 11), Tokyo, August 1991, pp. 25-28.

4. Gradetsky V., Knyazkov M., Sukhanov A., Semenov E., Chashchukhin V., Kryukova A., 2017. Possibility of Using Wall Climbing Robots for Underwater Application. Proceed. of CLAWAR-2017 Intern. Conference, Human-Centric Robotics, Porto, Portugal. Sept. 2017, pp. 239-246.

5. Kozlov D., Pavlov A., Yaschuk V., The Mathematical Model of the Gas-Liquid Ejector with the Straight Mixing Chamber. Izvestia of Volgograd State Technical University, 2010, pp. 8-11.

6. Gradetsky V.G., Knyazkov M.M., Semenov E.A., Sukhanov A.N. Adaptive gripping devices of mobile robots with miniature ejectors // Mechatronics, Automation, Control, 2016. V. 17, No. 3, p. 172-177.

7. Gradetsky V.G., Knyazkov M.M., Semenov E.A., Sukhanov A.N. Dynamic processes in vacuum contact devices of vertical movement robots in the aquatic environment / MAU 2019, Volume 20, No. 7, p. 417-420.

8. Gradetsky V., Knyazkov M., Sukhanov A., Semenov E., Chashchukhin V., Kryukova A. Possibility of Using Wall Climbing Robots for Underwater Application // Proceed. of CLAWAR-2017 Intern. Conference. Human-Centric Robotics, Porto, Portugal, Sept. 2017. P. 239-246.

9. Huterkamp H., Bach Fr.-W., Ogawa Y., Rachkov M. Climbing Robot for Underwater Cutting // Proc. International Conf. on Oceans Engineering, OCEANS. 1994. Vol. 1. P. 602-607.

10. Huterkamp H., Bach Fr.-W., Rachkov M., Seevers J. Clinbing Robot for UnderwaterCleaning // Proc. 5th International Offshore and Polar-Engineering Conf., Hague. 195. Vol. 2. P. 305-311.

11. Kitowski Z., Garus J. Control of Motion of Underwater Robot Under Condition of External Disturbances // Proc. 7th International Conf. on Advanced Robotics, ICAR'95, Sant Fetiu de Guixols, September 1995. Vol. 1. P. 278-282.

12. Rachkov M. Testing of the WCRs' Grippers by the Simulation Systems // Proc. of the Radio Conf., Moscow. 1990. Vol. 2. P. 22-24.

13. Robotics in Nuclear Facilities, 1991 // Special Issue for Exhibitions of the 11th International Conference on Structural Mechanics in Reactor Technology (SmiRT 11). Tokyo. August 1991. P. 25-28.

14. Yamafuji K., Gradetsky V., Rachkov M., Semenov E. Mechatronic Drive for Intelligent Mobile Wall Climbing Robots // Robotics and Mechatronics. 1993. Vol. 5. N. 2. P. 164171. 